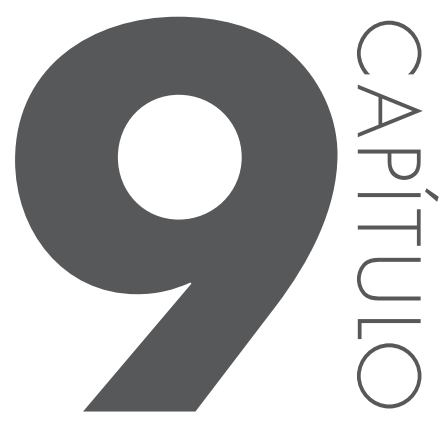

\title{
ACESSIBILIDADE E MOBILIDADE NO PARQUE DO SABIÁ NA CIDADE DE UBERLÂNDIA (MG)
}

Melo, Cristiane Aparecida Silva Moura '; Orlando, Paulo Henrique Kingma ${ }^{2}$;

' Mestranda em geografia da UFG - Regional Catalão

2 Professor Doutor do Programa de Pós graduação em Geografia da UFG - Regional

Catalão

* email: crisapa3179@gmail.com.br

\section{RESUMO}

Este trabalho é fruto de uma pesquisa sobre as questões que tangem a necessidade de que exista um planejamento urbano com infraestrutura voltada para a criação de áreas verdes que no trabalho faz referência ao parque do Sabiá, primeiro parque urbano criado na cidade de Uberlândia (MG). Assim o objetivo deste é realizar a análise da infraestrutura do parque do Sabiá verificando se a mesma é acessível para pessoas com deficiência e pessoas com mobilidade reduzida. Para a composição do trabalho foi realizada um levantamento bibliográfico em materiais já publicados que tratam da temática bem como a lei $\mathrm{n}^{\mathrm{o}} 10.098$ de Dezembro de 2000 de acessibilidade, ${ }^{\circ} 12.587$ 
de Janeiro de 2012 e a norma técnica 9.050 de 2004, da Associação Brasileira de Normas Técnicas - ABNT. Ainda foram realizados trabalhos de campo para observar se os aspectos estruturais do Parque do Sabiá estão em conformidade às normas citadas.

Palavras-chave: Acessibilidade; mobilidade, parque do Sabiá

Melo, Cristiane Aparecida Silva Moura; Orlando, Paulo Henrique Kingma; "ACESSIBILIDADE E MOBILIDADE NO PARQUE DO SABIÁ NA CIDADE DE UBERLÂNDIA (MG)", p. 148-163. In: Seminário de Pesquisa, Pós-Graduação e Inovação da Regional Catalão (2. : 2014 : Goiás) Coletânea Interdisciplinar em Pesquisa, Pós- Graduação e Inovação - Volume 1 : Estudos Ambientais, Território e Movimentos Sociais. Anais [livro eletrônico] / organizado por Adriana Freitas Neves, Idelvone Mendes Ferreira, Maria Helena de Paula, Petrus Henrique Ribeiro dos Anjos. São Paulo: Blucher, 2015. ISBN: 978-85-8039-109-1, DOI 10.5151/9788580391091-V1_Cap09 


\section{INTRODUC̣ÃO}

Sabe-se que o processo de urbanização provocou várias modificações na organização das atividades no espaço. Dentre essas modificações ocorreram o êxodo rural e os inchaços dos espaços urbanos. Assim esses inchaços urbanos acarretaram em uma nova dinâmica no espaço urbano e como consequência ocorre os impactos ambientais de forma desordenada e sem a menor preocupação com a preservação e conservação do meio ambiente.

No Brasil o processo de urbanização foi intensificado a partir da década de 1960 com a ampliação dos parques industriais das cidades de São Paulo e Rio de Janeiro, cidades brasileiras que se desenvolveram mais rapidamente, pois na primeira havia um grande acúmulo de capital devido a cultura do café enquanto a segunda até esta década foi a capital do país. Como resultado desses fatores ocorreu um intenso processo de urbanização nestas duas cidades.

Segundo dados do Instituto Brasileiro de Geografia e Estatística (IBGE), a população urbana no Brasil na década de 1960 era de 45,5\%, na década seguinte (1970) esse número era 55,9\%, enquanto no ano 2010 esse número subiu para $84 \%$.

A partir disso verifica-se que a população urbana cresceu e junto com ela a necessidade de novas moradias. A parcela do solo nas proximidades do centro urbano possuía uma maior valorização fruto do processo de especulação imobiliária, por este motivo as pessoas que chegavam as grandes cidades procuravam as áreas mais periféricas da malha urbana, devido aos menores preços dos imóveis e dos aluguéis.

Em decorrência do alto valor da reprodução de vida nas capitais, o interior do Brasil com destaque par a região sudeste passa sofrer um intenso processo de urbanização o que acarretou em um processo de interiorização do país e com a cidade de Uberlândia (MG), não foi diferente segundo dados do IBGE (2010) esta cidade é a segunda maior cidade do estado de Minas Gerais. Isso se deve ao fato que no inicio do século XX a cidade de Uberlândia (MG) servia como passagem de tropeiros que transportavam mercadorias do estado de São Paulo para o de Goiás e a partir da década de 1910 com a implantação da estrada de ferro Mogiana, que levou ao desenvolvimento da cidade, consolidando-a como um grande centro logístico.

O rápido crescimento da cidade de Uberlândia $(\mathrm{MG})$ acarretou em uma infraestrutura inadequada à locomoção de pessoas com mobilidade reduzida e deficientes, em várias regiões da cidade. Isso é resultado da falta de políticas públicas eficientes que solucionem os problemas relacionados a mobilidade e 
acessibilidade urbana em locais públicos e privados.

Apesar de em muitas regiões a infraestrutura ser inadequada, a região central da cidade de Uberlândia (MG) é tida como referencia no que tange acessibilidade, já que boa parte das calçadas possuem rampas de acesso, há presença de faixas de pedestre, possui uma sinalização vertical e horizontal, porém há uma série de obstáculos na calçada. Em relação ao restante da cidade a prefeitura municipal se preocupa com o transporte dos deficientes. $\mathrm{Na}$ última licitação para o transporte público, há exigência de ônibus dotados de rampas para facilitar o acesso das pessoas com deficiência na periferia, além de ofertar o transporte porta a porta para as pessoas com mobilidade reduzida e deficientes físicos.

Isso é resultado de um processo histórico de reivindicações da população sensível a causa juntamente com os deficientes físicos e das pessoas com mobilidade reduzida que lutaram pelo direito de locomoção e acessibilidade dentro da malha urbana da cidade de Uberlândia (MG) além da inserção dos mesmos no mercado de trabalho.

Em decorrência da necessidade das pessoas em trabalhar, estudar e desenvolver outras atividades é necessário que elas tenham momentos de lazer voltados para o contato com a natureza, a fim de obter um momento de tranquilidade e sair do cotidiano urbano. Assim no lugar o cidadão expressa o seu modo de vida nele o homem convive com uma constante pressão devido à poluição sonora, atmosférica, ao transito intenso. Para isso foi criado o parque do Sabiá.

Em detrimento disto o parque do Sabiá na cidade de Uberlândia (MG) foi criado como um local para que as pessoas tenham momentos de lazer e prazer no que tange o contato com a natureza e ao divertimento. Porém muitas das pessoas frequentam as áreas do parque possuem mobilidade reduzida ou algum tipo de deficiência.

A partir disso o trabalho propõe realizar o estudo da acessibilidade do parque do Sabiá na cidade de Uberlândia (MG) a análise será da infraestrutura, observando as barreiras físicas e naturais que prejudicam o acesso a esses, observando se eles estão atendendo as leis federais $n^{\circ} 10.098$ de 19 de dezembro de 2000 e a n 12.587 de janeiro de 2012, além das normas da Associação Brasileira de Normas Técnicas 9.050. 


\section{DESENVOLVIMENTO}

Para a criação do parque foi criada a decreto municipal no 1.925 de 28 de junho de 1971, porém a sua construção foi iniciada em 1977.

O Parque do Sabiá segundo dados da Prefeitura Municipal de Uberlândia, foi criado pelo decreto municipal $n^{\circ} 1.925$ de 28 de junho de 1971, porém a sua construção foi iniciada em 1977, foi o primeiro a ser criado na cidade com o intuito de ser uma área de lazer para a população Uberlandense (pessoas nascidas no município de Uberlândia) e Uberlandina (pessoas nascidas em outros municípios que migraram para Uberlândia). Para a sua administração foi criada a FUTEL (Fundação Uberlandense de Turismo, Esporte e Lazer) através da lei municipal 2.759.

O Parque possui uma área verde com bioma característico do Cerrado Stricto Senso com $35.000 \mathrm{~m} 2$ bem conservados, na qual são distribuídas mesas com bancos de concreto, nas quais a população pode utilizar para a socialização com as demais pessoas, bem como observar a natureza. Dentro do parque ainda há as trilhas ecológicas para a visitação da fauna e dos mananciais de água.

Possui uma boa rede hidrográfica composta por três nascentes que dão origem ao microbacia do Jataí (canalizado na Avenida Doutor Anselmo Alves), abastecendo as sete represas dentro do parque. Estas nascentes dão origem a um lago artificial que possui um criatório de peixes, há ainda duas piscinas que são abertas aos visitantes.

Há um zoológico composto por vários animais característicos da fauna do cerrado com exceção de casal de leões, um aquário, ambos abertos a visitação pública. Há um deck na represa com peixes ornamentais.

No parque do Sabiá existe um horto municipal, um viveiro, com mudas de espécies arbóreas da flora do cerrado e plantas ornamentais que são utilizadas pela prefeitura para a arborização da cidade, bem como o embelezamento de praças e locais públicos elas também são distribuídas a população.

Há ainda uma pista de cooper de 5.100 metros de extensão, quadras poliesportivas, campos de futebol de grama, uma quadra de areia, equipamentos para a prática de exercícios físicos. Um parque infantil com diversos brinquedos que são divididos por faixa etária sendo a maior de 10 anos de idade. Há banheiros, vestiários, lanchonetes, dentre outros equipamentos que fazem parte do mobiliário urbano.

No local há o desenvolvimento de atividades relacionadas à educação ambiental, o parque recebe a visita de escolas públicas e privadas, universidades federais e privadas, conta também com uma sala com animais da fauna do 
cerrado empalhados, biblioteca com materiais pertinentes a flora e fauna característica do cerrado.

No ano de 2010 na gestão do ex-prefeito Odelmo Leão o parque passa por um processo de revitalização o qual reformou áreas já existentes e criou novas como o recanto do Sabiá, as academias populares dispostas na pista de cooper. A proposta disso é que a área de lazer se tornasse acessível a toda a população. A figura 1 demonstra uma visão da área do Parque do Sabiá.

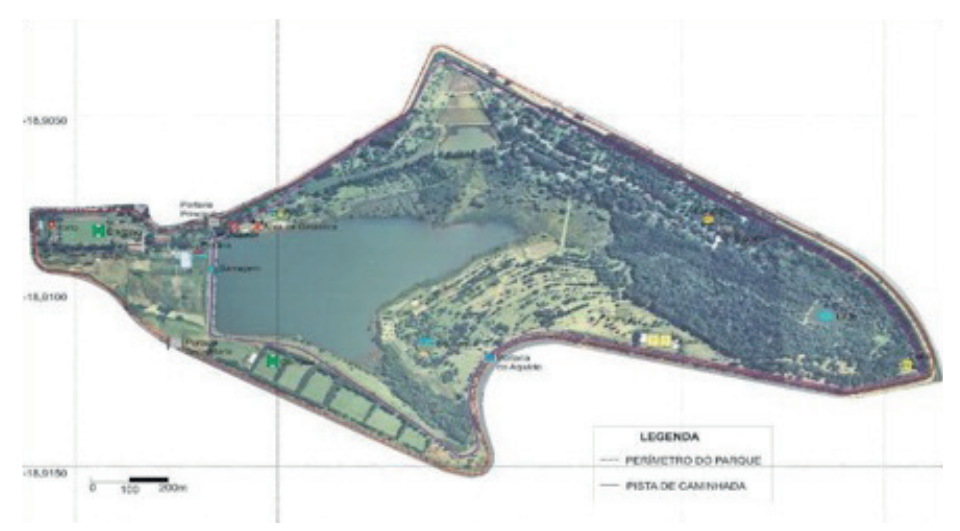

Figura 1: Vista da área do parque Fonte: MENDES, L. F. 0.

Assim para a análise da infraestrutura foi criada um quadro que atendesse as deficiências dos idosos, cadeirantes, surdos e cegos, ela foi confeccionada atendendo os requisitos da lei $\mathrm{n}^{\circ} 10.098$ de acessibilidade e a NBR 9.050. $\mathrm{O}$ intuito do quadro é que ele atenda os parâmetros necessários para que a infraestrutura do parque que passou por um processo de revitalização atenda as necessidades de todos os visitantes.

Partindo desse quadro foram selecionados os pontos de interesse dos visitantes, ou seja, foram selecionadas 4 áreas utilizada pelos usuários e visitantes (recanto do Sabiá, zoológico, mundo da criança e deck dos peixes) áreas de lazer que serão expostos juntamente com a análise da sua infra estrutura. 


\section{Quadro 1: Parâmetros de acessibilidade}

\begin{tabular}{|c|c|c|c|c|}
\hline $\begin{array}{l}\text { PARAMÊTROS DE } \\
\text { ACESSIBILIDADE }\end{array}$ & CADEIRANTE & IDOSO & SURDO MUDO & DEFICIENE \\
\hline $\begin{array}{l}\text { Altura do bebedouro de 0,73 metro } \\
\text { para uso sentado sem copo }\end{array}$ & $x$ & & & \\
\hline $\begin{array}{l}\text { Altura do bebedouro de } 0,90 \text { metro } \\
\text { para uso sentado com copo }\end{array}$ & $x$ & & & \\
\hline $\begin{array}{l}\text { Altura do bebedouro de } 1,00 \text { - } \\
1,20 \text { metro para uso em pé }\end{array}$ & & $x$ & $x$ & $x$ \\
\hline $\begin{array}{l}\text { Área para manobra de } 180^{\circ} \\
-1,50 \times 1,20 \text { metro }\end{array}$ & $x$ & & & \\
\hline $\begin{array}{l}\text { Área para manobra de } 360^{\circ} \\
-1,50 \times 1,50 \text { metro }\end{array}$ & $x$ & & & \\
\hline $\begin{array}{l}\text { Área para manobra de } 90^{\circ} \\
1,20 \times 1,20 \text { metro }\end{array}$ & $x$ & & & \\
\hline Ausência de degraus & $x$ & & & $x$ \\
\hline $\begin{array}{l}\text { Barras de apoio de } 3 \text { a } \\
4,5 \mathrm{~cm} \text { de diâmetro }\end{array}$ & & $x$ & $x$ & $x$ \\
\hline $\begin{array}{l}\text { Barras de apoio de } 3 \text { a } 4,5 \mathrm{~cm} \\
\text { de diâmetro nos sanitários }\end{array}$ & $x$ & $x$ & & $x$ \\
\hline $\begin{array}{l}\text { Faixa live na calcada } \\
\text { de 1,20 metros }\end{array}$ & $x$ & $x$ & $x$ & $x$ \\
\hline $\begin{array}{l}\text { Presença de elevador para } \\
\text { passár de um piso ao outro }\end{array}$ & $x$ & $x$ & & $x$ \\
\hline Piso liso sem degraus & $x$ & & & $x$ \\
\hline Piso tátil & & & & $x$ \\
\hline $\begin{array}{l}\text { Quantidade de sanitários } \\
\text { adaptáveis no mínimo } 1\end{array}$ & $x$ & $x$ & $x$ & $x$ \\
\hline Rampas de acesso de $3^{\circ}$ a $5^{\circ}$ & $x$ & $x$ & $x$ & $x$ \\
\hline Rebaixamento da calçada & $x$ & & $x$ & $x$ \\
\hline Sanitários em rotas acessiveis & $x$ & $x$ & $x$ & $x$ \\
\hline Sinalização em braile & & & & $x$ \\
\hline Sinalização sonora & & & & $x$ \\
\hline Sinalizacãoo visual & & & $x$ & \\
\hline
\end{tabular}

Fonte: NBR 9050, lei n0 10.098. Org. MELO, C. A. S. M. 


\section{RECANTO DO SABIÁ}

O espaço possui um jardim. É bem arborizado, na entrada há uma rampa para o acesso de pessoas com mobilidade reduzida e uma escada (ambas possuem barras de apoio dentro dos padrões da NBR 9050) gerando duas opções para o visitante acessar o local. Na sequencia é possível visualizar uma série de mesas com bancos. Há a disponibilidade de acesso a rede de internet wi-fi gratuita. $\mathrm{Na}$ entrada também é possível visualizar uma pequena cascata. $\mathrm{O}$ piso do local é confeccionado em paralelepípedo. Nas proximidades há o recanto do atendimento e algumas lanchonetes que não possuem rampas de acesso, sendo possível acessar somente através de degraus ou escadas. A figura 2 mostram a infraestrutura do espaço.

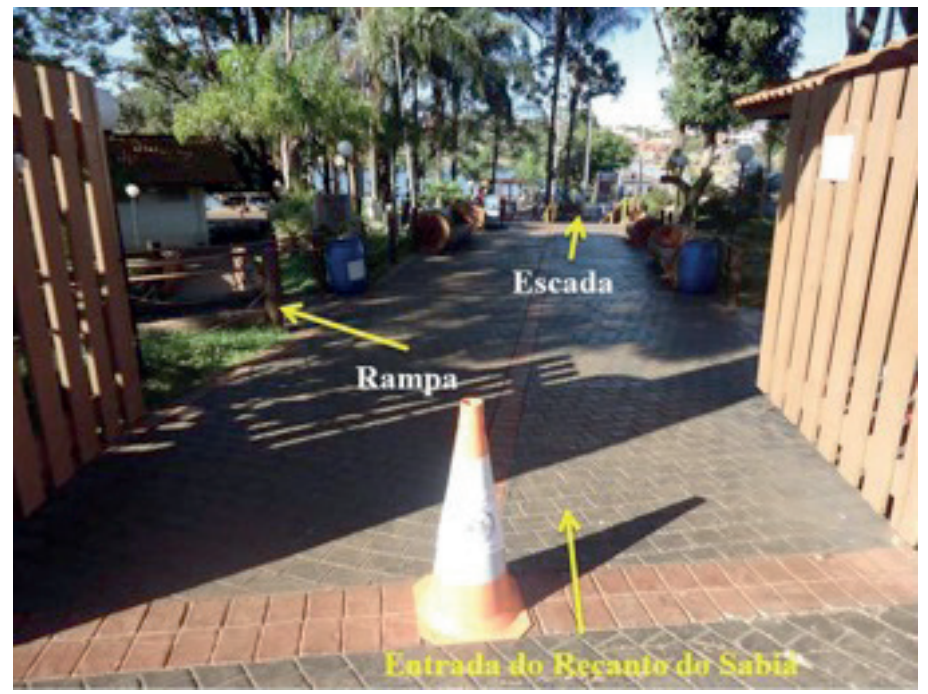

Figura 2: Infraestrutura do Recanto do Sabiá

Fonte: MELO, C. S. A. M., 2014.

No espaço ainda há as lanchonetes que vendem bebidas e alimentos, as mesmas possuem uma boa estrutura com grande espaço para o atendimento dos visitantes, porém o acesso ao local é difícil, pois há degraus para o acesso do local.

O importante é a acessibilidade que o espaço possui, pois é composto por aparelhos adaptados para os cadeirantes e demais pessoas com deficiência preocupação com a parcela da população detentora de mobilidade reduzida. 


\section{ZOOLÓGICO}

Possui piso de paralepipedo que é irregular o que dificulta o deslocamento de pessoas com mobilidade reduzida e deficientes. Há placas de sinalização das espécies. Os viveiros onde ficam os animais expostos para visitação possuem uma barra de proteção que dá distancia entre o visitante e o viveiro. A figura 3 demonstra a infraestrutura.

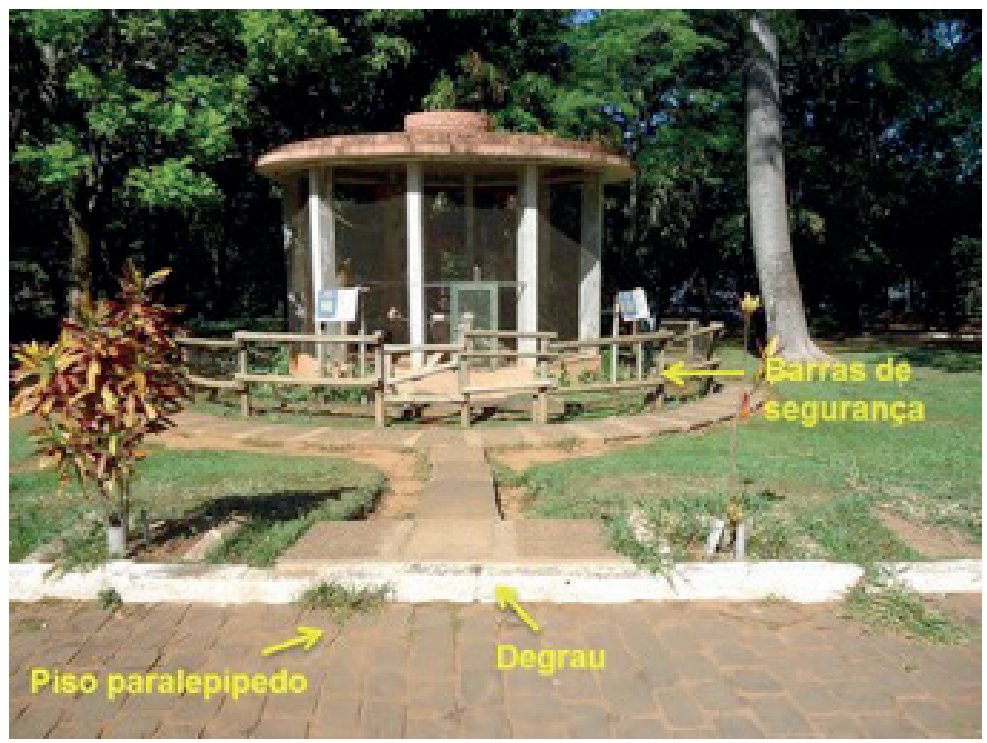

Figura 3: Infraestrutura do zoológico

Fonte: MELO, C. S. A. M., 2014

Através da analise do espaço é possível verificar que o mesmo não fornecesse nenhum tipo de acessibilidade, visto que não existe um piso regular e rampas de acesso o que facilita a mobilidade do visitante.

\section{MUNDO DA CRIANÇA}

O espaço foi construído a fim de promover a recreação e o lazer de crianças até 10 anos de idade. A utilização é aberta todos os dias da semana para mães e pais que levam os seus filhos, para momentos de diversão e convívio com outras crianças.

A área é composta por vários tipos de brinquedos que foram confeccionados utilizando como matérias primas aço, madeira, pneus e borracha. Fato que diminuiu o valor dos custos. Além dos brinquedos há dispostas mesas com 
bancos de cimento que ficam sobre o paralelepípedo. As figuras 4 e 5 retratam a localização dos brinquedos e a disposição das mesas.

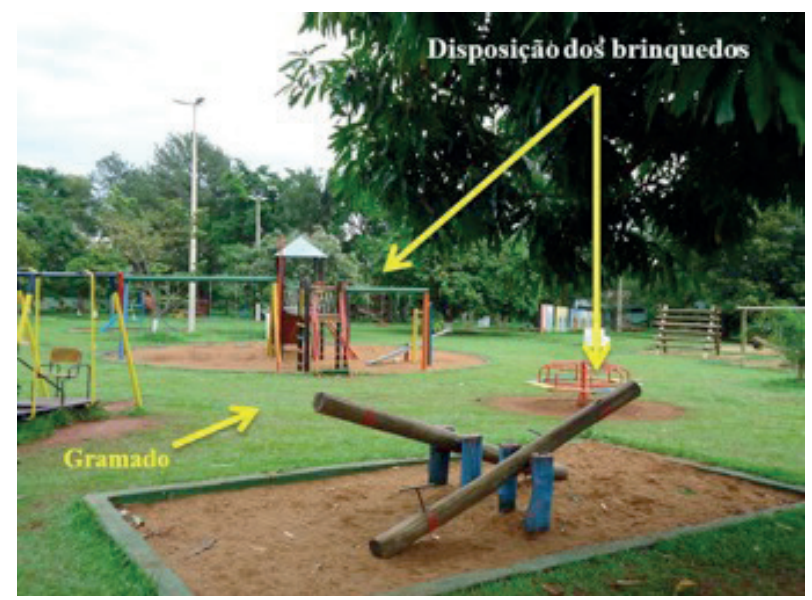

Figura 4: Disposição dos brinquedos

Fonte: MELO, C. S. A. M., 2014.

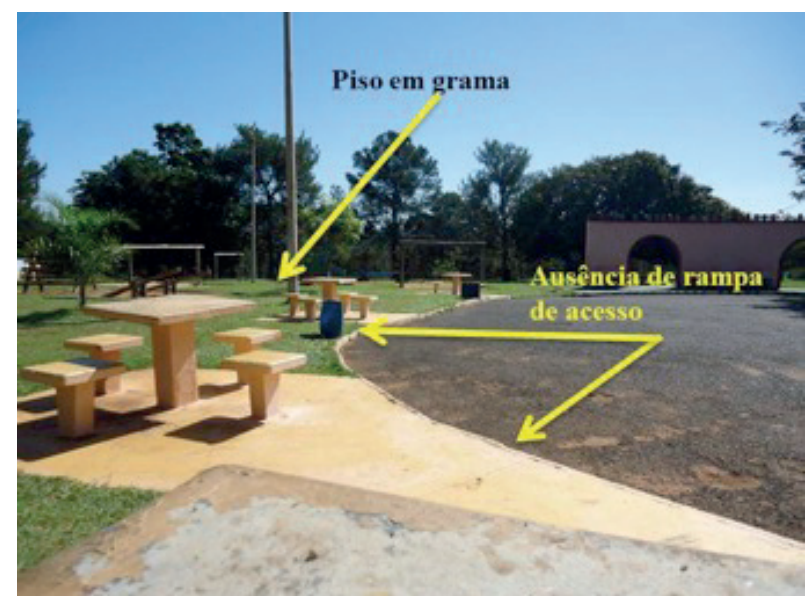

Figura 5: Disposição das mesas e acesso ao Mundo da Criança Fonte: MELO, C. S. A. M., 2014.

Sobre as figuras acima é possível averiguar que os brinquedos ficam sobre uma área de gramado, a qual dificulta o acesso de pessoas com mobilidade reduzida e cadeirantes, com destaque para o segundo citado, pois de forma alguma é possível que estas pessoas se desloquem de um lugar ao outro, dificultando a sua mobilidade.

Também não há piso tátil, sinalização sonora e visual, tornando difícil a 
identificação de informações básicas incluindo o nome do espaço para a sua identificação. Há apenas uma fachada no formato de castelo.

Há bebedouros confeccionados de cimento com azulejos que dão acabamento cada um com duas torneiras que variam de 50 a 90 centímetros sem o recuo para o encaixe de uma cadeira de rodas. Além de estarem distribuídos no espaço com presença de grama, o que dificulta a mobilidade.

Outro agravante são os banheiros, separados em feminino e masculino, que não possui uma passarela com piso tátil e que dê acesso a cadeirantes. Em tese possui um sanitário adaptado, porém não possui barras de apoio e o espaço de 1,20 x 1,20 metro que permitiria a um cadeirante realizar uma manobra de $90^{\circ}$. Não possui lavatórios adequados para o mesmo, e inclusive sem presença de torneiras.

Cabe ressaltar que no espaço onde estão inseridos os brinquedos, há dificuldades em adaptar o espaço para o uso de deficientes, visto a necessidade que os estes fiquem dispostos em piso de areia e grama.

\section{DECK RECANTO DOS PEIXES}

Através da analise do espaço é possível verificar que para o acesso ao espaço há um rebaixamento de calçada deteriorado necessitando de reparos, a porta de entrada possui largura que atende as regras da NBR 9050, o piso do Deck foi confeccionado em madeira estando o mesmo bem conservado. E existe um guarda corpo que dá proteção aos usuários do lugar. A figura 6 mostra parte da área física.

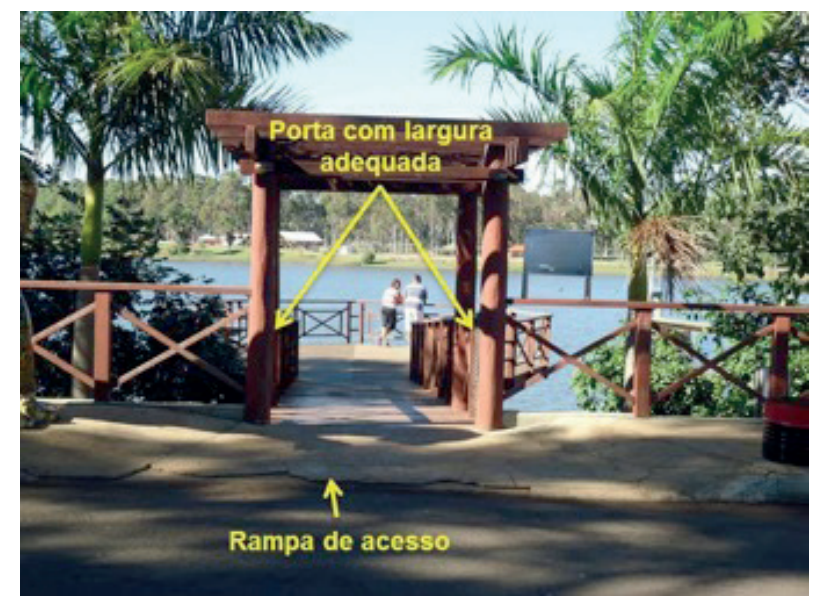

Figura 6: Área física do deck

Fonte: MELO, C. S. A. M., 2014. 
De uma forma geral o espaço é acessível tanto para os deficientes quanto as pessoas com mobilidade reduzida.

\section{CONCLUSÃO}

Em uma análise geral da infraestrutura do parque do Sabiá que foi o primeiro a ser criado na malha urbana cidade de Uberlândia ( $M G)$ nota-se que é um espaço bem consolidado. É o mais frequentado pela população uberlandense por oferecer várias atividades de lazer.

Passou por um processo de revitalização no ano de 2010 que reformulou várias áreas do parque além da criação de outras em uma analise geral possui áreas acessíveis aos deficientes físicos, embora ainda deixe a desejar como no zoológico que é de difícil acesso dos cadeirantes. Enquanto o recanto do Sabiá e o deck dos peixes possuem uma acessibilidade quase adequada, isso em decorrência do piso irregular. $\mathrm{O}$ mundo da criança fica a desejar no que tange a acessibilidade devido as calçadas com os degraus mais altos.

Dentre outras questões ainda há o que melhorar na infraestrutura do parque como a padronização dos pisos, construção de rampas de acesso nas calçadas, construção bebedouros acessíveis, desta forma os espaços destinados à observação da natureza e descanso passam a ser acessíveis para as pessoas que os frequentam. 


\section{Title: Accessibility And Mobility In The Park Sabiá In Uberlândia (Mg)}

\section{Abstract}

This work is the result of a research on the issues that concern the necessity that there is an urban planning with infrastructure aimed at creating green areas that work makes reference to the Sabia first urban park created in the city of Uberlândia (MG) park. Thus the aim of this is to perform the analysis of the Sabia park infrastructure checking if it is accessible for the disabled and people with reduced mobility. For the composition of the work in a literature already published materials that deal with the topic as well as Law No. 10,098 of December 2000 Accessibility, No. 12.587 of January 2012 and the technical standard 9050, 2004, the Brazilian Association of Standards was held techniques - ABNT. Although field work was carried out to see whether the structural aspects of the Park Sabia conform to the standards listed.

Keywords: Accessibility; mobility; park Sabia 


\section{REFERÊNCIAS}

BRASIL. Lei n 9.985 , de 18 de julho de 2000. Sistema Nacional de Unidades de Conservação da Natureza. Disponível em: < http://www.planalto.gov.br/ccivil_03/leis/L9985.htm>. Acesso em: 01 de Janeiro de 2014. . Lei $n^{0} 10.098$, de 19 de dezembro de 2000. Acessibilidade das pessoas portadoras de deficiência ou com mobilidade reduzida. Disponível em: < http://www.planalto.gov.br/ccivil_03/leis/110098.htm >. Acesso em: 01 de Janeiro de 2014.

Norma Brasileira ABNT NBR 9050. Disponível em < http://www.uberlandia.mg.gov.br/midia/ documentos/planejamento_urbano/norma_abnt_acess.pdfs. Acesso em: 15 de Dezembro de 2012.

CAMBIAGHI, Silvana. Desenho Universal: métodos e técnicas para arquitetos e urbanistas. SENAC2. São Paulo: 007 CASTELLS, Manuel. A questão urbana. Tradução Caetano, A. Paz e terá. Rio de Janeiro: 1983.

CORRÊA, Roberto Lobato. 0 espaço urbano. Ática. São Paulo: 1989.

DUARTE, Fabio. Planejamento Urbano. 20 ed. Ibpex. Curitiba: 2007.

Instituto Brasileiro de Geografia e Estatística. População. Disponível em: <www.ibge.gov.br>. Acesso em 28 de Maio de 2014.

Instituto Brasileiro dos Direitos das Pessoas com Deficiência. Disponivel em: <http://www.ibdd.org.br>. Acesso em 28 de Maio de 2014.

LEFEBVRE, Henry. 0 direito à cidade. Tradução FRIAS, R. E. Centauro. São Paulo: 2001.

LIMA, Samuel do Carmo.; ROSA, Roberto.; FELTRAN FILHO. Mapeamento do uso do solo no municíio de Uberlândia-MG, através de imagens TM/LANDSAT. Revista Sociedade e Natureza,Uberlândia, v.1, n.2, p.127 - 145, 1989.

LOPES, Valéria Maria Queiroz Cavalcante. Uberlândia: histórias por entre trilhas, trilhos e outros caminhos: memórias, construção e apropriação dos espaços. EDUFU. Uberlândia:2010.

MARICATO, Ermínia. As ideias fora do lugar e o lugar fora das ideias - planejamento urbano no Brasil. In: org. ARANTES, Otilia. VAINER, Carlos.; , MARICATO, Ermínia. A cidade de pensamento único. Vozes. Petrópolis, Rio de Janeiro: 2000.

. Habitação e cidade. 2ed. Atual. São Paulo: 1997.

MOTA, Suetônio. Urbanização e Meio Ambiente. ABES. Rio de Janeiro: 1999.

NIESS, Pedro Henrique Távora.; NIESS, Luciana Toledo Távora. Pessoas Portadoras de Deficiência no Direito Brasileiro. Juarez de Oliveira. São Paulo: 2003.

Prefeitura Municipal de Uberlândia. Cartilha de acessibilidade. Disponivel em < http://www.uberlandia.mg.gov. br/uploads/cms_b_arquivos/2982.pdff. Acesso em: 02 de Outubro de 2013.

. Decreto municipal 1925. Criação do Parque do Sabiá. Disponível em < http://www.uberlandia.mg.gov.br >. Acesso em: 10 de Outubro de 2013.

Decreto $n^{0}$ 11.666, de 11 de maio de 2009. Disponível em < http://www.uberlandia.mg.gov.br/ procura.php?cx=015560453420260481 102\%3Ai3i8zzyxxk\&\&cof=FORID\%3A1 1 \&ie=UTF-8\&q=decreto+11666>. Acesso em: 10 de Outubro de 2013.

Decreto $n^{0} 11.768$, de 23 de julho de 2009. Disponível em < http://www.uberlandia.mg.gov.br/procura.php? $c x=0$ 15560453420260481102\%3Ai3i8zzyxxk\& \&of=FORID\%3A1 1 \&ie=UTF-8\&q=decreto+1 1768>. Acesso em: 10 de Outubro de 2013. 
FUTEL. Disponivel em < http://www.uberlandia.mg.gov.br/uploads/cms_b_arquivos/6019.pdf > . Acesso em: 10 de Outubro de 2013.

Lei 1.925 de 28 de junho de 1971. Criação do Parque do Sabiá. Disponível em < http://www. uberlandia.mg.gov.br >. Acesso em: 10 de Outubro de 2013.

. Parques Municipais de Uberlândia. Disponível em < http://www.uberlandia.mg.gov.br/?pagina=secr etariasOrgaos\&s=51\&pg=147>. Acesso em: 02 de Janeiro de 2013.

ROLNIK, Raquel. 0 que é cidade? 3. ed. São Paulo: brasiliense, 1994.

SANTOS, Milton. A urbanizaccão brasileira. 5 ed. São Paulo: Editora USP, 2005.

USP. São Paulo: 2008.

. Metamorfoses do espaço habitado: fundamentos teórico metodológicos da Geografia. 6 ed. Editora SANTOS, Milton. SILVEIRA, Maria Laura. 0 Brasil: Território e sociedade no início do século XXI. 10ed. Record. Rio de Janeiro-São Paulo: 2008

SOARES, Beatriz Ribeiro. et al. Uberlândia (MG): leituras geográficas de uma cidade média em transição. In: Agentes econômicos e reestruturação urbana e regional: Tandil e Uberlândia. Org. ELIAS, D., SPOSITO, M. E. B., SOARES, B. R. Expressão Popular. São Paulo: 2010. p. 157 - 280.

SOUZA, Marcelo Lopes. Mudar a cidade: uma introdução crítica ao planejamento e à gestão urbanos. Bed. Bertrand Brasil. Rio de Janeiro: 2011.

VIANNA, Ilca Oliveira de Almeida. Metodologia do trabalho cientifico: um enfoque didático da produção cientifica. E.P.U. São Paulo: 2001. 
Seminário de Pesquisa, Pós-Graduacãoo e Inovação da Regional Catalão 